\title{
Evaluation of the Antifungal Activity of the Extracts of the Rhizome of Alpinia Nigra
}

\author{
R. S. C. G. Rajapaksha ${ }^{1}$, W. J. Wickramarachchi ${ }^{2}$, K. G. D. M. Hansini ${ }^{1}$
}

\begin{abstract}
The study was aimed to investigate the bioactivity in the fresh extract of the rhizome of Alpinia nigra using antifungal activity against human skin infections causative fungi Malassezia furfur and Microsporum gypseum. Fresh rhizome of A. nigra was subjected to steam distillation and the essential oil was separated using solvent extraction. The antifungal activity of the extract was evaluated using disk diffusion method. Highest inhibition for $M$. furfur was observed at the dose of $400 \mu \mathrm{g}$ with a mean diameter of the inhibition zone $(2.1 \pm 0.09) \mathrm{cm}$ and for $M$. gypseum the diameter was $(2.4 \pm 0.05) \mathrm{cm}$. The results confirmed that the extract of $A$. nigra shows antifungal activity on the growth of $M$. furfur and $M$. gypseum. Hence it is confirmed that A.nigra have the potential to cure the dermal infections.
\end{abstract}

Keywords - Antifungal, Alpinia nigra, Disk diffusion, Malassezia furfur, Microsporum gypseum

\section{INTRODUCTION}

$\mathrm{M}$ EDICINAL plants are the richest natural sources of medicinal products used in traditional and orthodox medicine [1]. The search for medicinal values of different plants has attracted increasing interest in the past couple of decades, presumably because of their potential as sources of potent pharmacological activities, convenience to users, economic viability, as well as low toxicity [1]. Alpinia nigra in Sinhalese "Kaluwa Ala" is a plant, which used in traditional medicinal system in Sri Lanka and belongs to the Zingiberaceae family. It is an herbaceous plant that grows well on riverside and can also grow on moist land. The underground stem is rhizome and aerial stem is pseudo-stem which consists of leaf sheath, approximately 3.08 meters in height. Leaves are simple, alternate, oblong, entire and acute at base and apex of the plant with very short petiole and very long leaf sheath with small ligule (Figure 1) [2]. The rhizome of A. nigra represents largely untapped resource of bioactive compounds such as antifungal activities as playing important medicinal role. In Sri Lanka, the fresh extract of this rhizome is used to treat the fungal infections in the skin such as Pityriasis versicolor. Malassezia furfur and Microsporum gypseum are some of the major causative fungi infected on human skin and known as cutaneous fungi [3]. A thorough

\footnotetext{
${ }^{1}$ Department of Dravyaguna Vignana (Ayurveda Pharmaceuticals), Gampaha Wickramarachchi Ayurveda Institute, University of Kelaniya, Sri Lanka.

${ }^{2}$ Department of Cikitsa, Gampaha Wickramarachchi Ayurveda Institute, University of Kelaniya, Sri Lanka.
}

literature survey revealed that the antifungal activities of $A$. nigra for such an infectious diseases have not been studied extensively and only a handful investigations have been found regarding the phytochemical and biological properties of the plant [1],[2],[4],[5]. The present study was carried out in order to investigate the bioactivity in the essential oil of the rhizome of A. nigra using antifungal activity against human skin infections causative fungi.

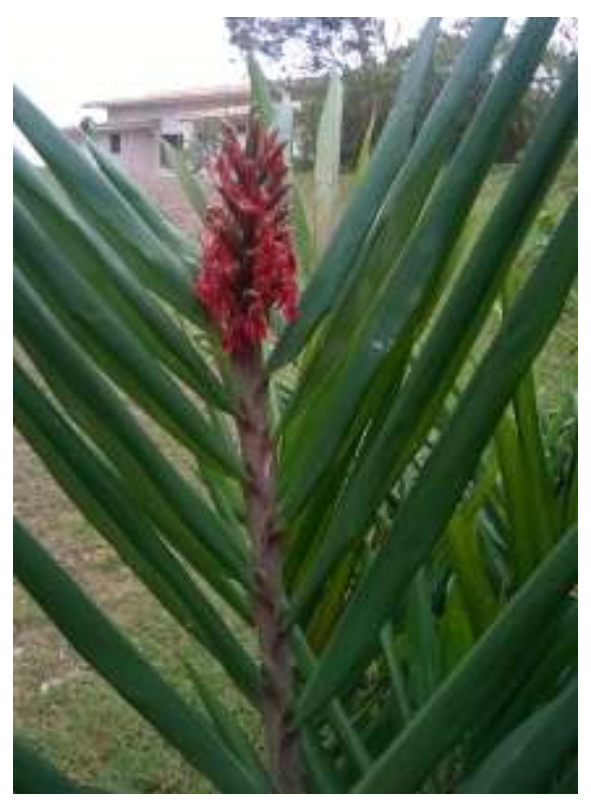

Fig 1: The plant of A.nigra

\section{MATERIALS AND METHODS}

\section{A. Sample collection and extraction}

The rhizomes of the plant A. nigra were collected from Haldummulla, Sri Lanka. The specimens of the plant were taxonomically identified and authenticated. The collected rhizomes were washed, cut into small pieces and dried in the shades of sun for about a week. The dried smaller parts were subjected to steam distillation and extracted aqueous layer with essential oil was separated into dichloromethane $\left(\mathrm{CH}_{2} \mathrm{Cl}_{2}\right)$ using separatory funnel. The organic solvent was evaporated and the remained essential oil was used for the antifungal bioassays. 


\section{B. Antifungal Assay}

Antifungal effects of these extracts were tested against two species of human skin infectious fungi, Malassezia furfur and Microsporum gypseum using disk diffusion method [6]. These fungi were cultured in a medium of Sabouraud Dextrose Agar (SDA). Spore suspensions of $M$. furfur and M. gypseum were prepared using seven days old pure cultures. Two drops $(0.1$ $\mathrm{ml}$ ) from the suspension was inoculated into sterilized petri dishes contained SDA and evenly distributed using sterilized glass spreader. Sterilized filter paper disks (5 mm diameter) were cut and four of them were placed on agar plates containing fungal suspension. Dimethyl Sulphoxide (DMSO) was used to dissolve the fungal extract. To prepare $1 \mathrm{mg} / \mathrm{ml}$ solution, $1 \mathrm{mg}$ of fungal extract was dissolved in $1 \mathrm{ml}$ of DMSO. Filter paper disks contained in agar plates were soaked with $50 \mu \mathrm{l}, 100 \mu \mathrm{l}, 200 \mu \mathrm{l}, 300 \mu \mathrm{l}$ and $400 \mu \mathrm{l}$ of each dissolved fungal extract separately. Parallel experiment was conducted with Fluconazole $(50 \mu \mathrm{l})$, a commercial fungicide recommended by the Department of Health, SL as positive control, and with DMSO $(50 \mu \mathrm{l})$ as negative control for comparison purposes. Each sample was replicated five times and arranged according to a Complete Randomized Design (CRD). All Petri dishes were sealed and kept under room temperature and observed the fungal growth daily.

\section{Data Analysis}

The data were analyzed using minimum concentration of the extract at which the fungus started to grow again was taken as the MIC and the minimum concentration at which the fungus did not show any growth again was taken as the MLC. All the data were statistically analyzed using MINITAB 14 statistical package.

\section{RESUlTS AND DisCUSSION}

Since there was no effect of DMSO $(50 \mu \mathrm{g})$ on the growth of $M$. furfur and $M$. gypseum it was used as the negative control and growth of $M$. furfur and $M$. gypseum were completely inhibited for Fluconazole, a synthetic antifungal compound $(50 \mu \mathrm{g})$ and used as the positive control in the antifungal assays carried out with the extracts.

The result of the antifungal activity of against $M$. furfur revealed that diameter of inhibition zone was increased with increasing dose of the extract. The mean diameter of the inhibition zones at the doses of $50 \mu \mathrm{g}, 100 \mu \mathrm{g}, 200 \mu \mathrm{g}, 300 \mu \mathrm{g}$ were $(0.8 \pm 0.6) \mathrm{cm},(0.9 \pm 0.06) \mathrm{cm},(1.4 \pm 0.08) \mathrm{cm},(1.7 \pm$ $0.3) \mathrm{cm}$ respectively. Highest dose of inhibition of $M$. furfur was observed at the dose of $400 \mu \mathrm{g}$ of the extract with a mean diameter of the inhibition zone $(2.1 \pm 0.09) \mathrm{cm}$. MIC and MLC values were $200 \mu \mathrm{g}$ and $300 \mu \mathrm{g}$ respectively (Fig 2).

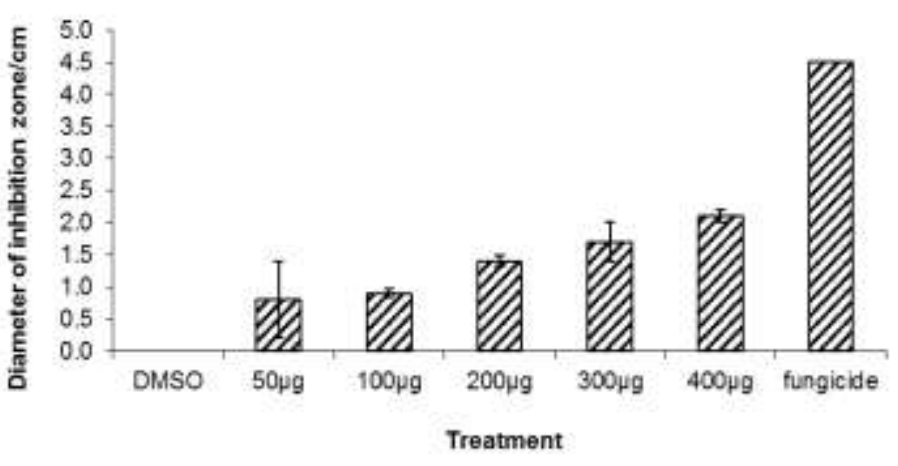

Fig 2: Antifungal activity of the extract of $A$. nigra against $M$. furfur

The graph displays in figure.3, shows the antifungal activity of the extract of A. nigra against M. gypseum. Observations of antifungal assay revealed that diameters of inhibition zones were increased with increasing the dose of the extract. The lowest mean diameter of the inhibition zone was $(0.6 \pm 0.5)$ $\mathrm{cm}$ at $50 \mu \mathrm{g}$. The diameter of inhibition zone at the dose of $400 \mu \mathrm{g}$ was $(2.4 \pm 0.05) \mathrm{cm}$. MIC and MLC values for the extract were $100 \mu \mathrm{g}$ and $200 \mu \mathrm{g}$ respectively.

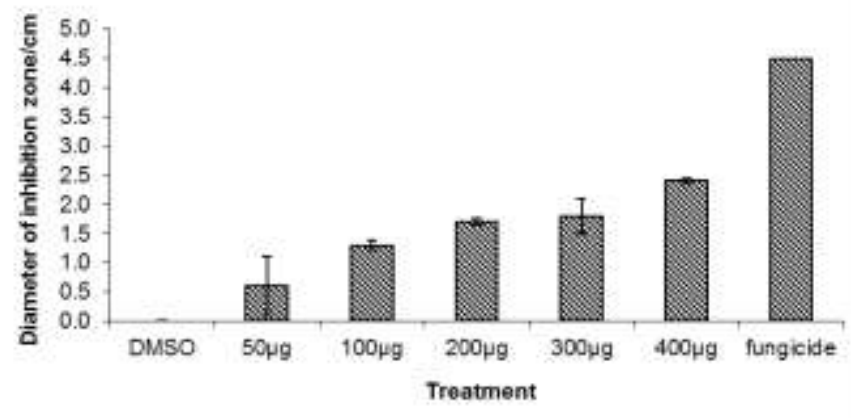

Fig 3: Antifungal activity of the extract of $A$. nigra against $M$. gypseum

In order to investigate the phytochemicals that playing antifungal activity, it is important to find out the major constituents of the A. nigra rhizome. A. nigra has two flavone glycosides, astragalin and kaempferol-3- $O$-glucuronide [7].

Even though there have been several researches conducted to evaluate the biological and phytochemical activities including antibacterial [8],[9], antioxidant [10],[11],[12], antiprotozoal [13], hepatoprotective [14] effects of the A. nigra, the responsible constituents were not identified yet. The above results confirmed that the extract of A. nigra shows antifungal effects on the growth of $M$. furfur and M. gypseum. Also it has been supported to verify the traditional uses of the rhizome of A. nigra to cure the fungi infected human skin as home remedies. Therefore, this study will be further extended in order to investigate the bioactive constituents encountered with the antifungal activity. 


\section{CONCLUSION}

Essential oil extract of the rhizome of A. nigra have the potential to inhibit the growth of Malassezia furfur and Microsporum gypseum, which cause dermal diseases in human.

\section{ACKNOWLEDGMENT}

Cultured fungi samples were provided by Medical Research Institute, Colombo 08, Sri Lanka.

\section{REFERENCES}

[1] Abu Ahmed A.M, Sharmen F, Mannan A, Rahman MA. Phytochemical, analgesic, antibacterial, and cytotoxic effects of Alpinia nigra (Gaertn.) Burtt leaf extract. J Tradit Complement Med. (2015);5:248-52. https://doi.org/10.1016/j.jtcme.2014.11.012

[2] Roy B, Swargiary A and Giri BR: Alpinia nigra (Family Zingiberaceae): An anthelmintic medicinal plant of North-East India. Advances in Life Sciences (2012), 2:39-51. https://doi.org/10.5923/j.als.20120203.01

[3] White T.C, Findley K, Dawson T.L. Jr, Scheynius A, Boekhout T, Cuomo C.A, Xu J, Saunders C.W. Fungi on the skin: dermatophytes and Malassezia. Cold Spring Harb Perspect Med; (2014), 4:a019802. https://doi.org/10.1101/cshperspect.a019802

[4] Das B.N, Biswas B.K, Anti-inflammatory activity of the rhizome extract of Alpinia nigra Int Res J Pharma, 2 (3) (2012), pp. 73-76

[5] Kanjilal, P.B and R. Kotoky. Essential oil composition of leaf and rhizome oil of Alpinia nigra (Gaertner) B. L. Burtt. from Northeast India. J. Essen. Oil Res., 2010;22: 358-359. https://doi.org/10.1080/10412905.2010.9700345

[6] Kannangara B. T. S. D. P., Rajapaksha R. S. C. G. and Paranagama P. A. Nature and bioactivities of endolichenic fungi in Pseudocyphellaria sp., Parmotrema sp. and Usnea sp. at Hakgala montane forest in Sri Lanka. Letters in Applied Microbiology, (2009);48 (203-209). https://doi.org/10.1111/j.1472-765X.2008.02512.x

[7] Qiao, C.F; Wang, Z.T; Dong, H; Xu, L.S; Hao, X.J; The chemical constituents of blackfruit galangal (Alpinia nigra), Chin Tradit Herb Drugs, 31 (2000), pp. 404-405

[8] Majinda R.R., Motswaledi M., Waigh R.D., Waterman P.G. Phenolic and antibacterial constituents of Vahlia capensis. Planta Med. (1997);63:268-270. https://doi.org/10.1055/s-2006-957671

[9] Panizzi L., Caponi C., Catalana S., Cioni P.L., Morelli I. In vitro antimicrobial activity of extracts and isolated constituentsof Rubusulmifolius. J Ethnopharmacol. (2002);79:165-168. https://doi.org/10.1016/S0378-8741(01)00363-4

[10] Apati P., Houghton P.J., Kery A. HPLC investigation of antioxidant components in Solidago herba. Acta Pharm Hung. (2004);74:223-231.

[11] Han J.T., Bang M.H., Chun O.K., Kim D.O., Lee C.Y., Baek N.I. Flavonol glycosides from the aerial parts of Aceriphyllum rossii and their antioxidant activities. Arch Pharm Res. (2004);27:390-395. https://doi.org/10.1007/BF02980079

[12] Plumb G.W., Price K.R., Williamson G. Antioxidant properties of flavonol glycosides from green beans. Redox Rep. (1999);4:123-127 https://doi.org/10.1179/135100099101534684

[13] Fernando C., Alma D.A. Additional Antiprotozoal flavonol glycosides of the aerial parts of Helianthemum glomeratum. Phytother Res. (2007);21:78-80. https://doi.org/10.1002/ptr.2031

[14] Singab A.N., Youssef D.T., Noaman E., Kotb S. Hepatoprotective effect of flavonol glycosides rich fraction from Egyptian Vicia calcarata Desf. against CCl4-induced liver damage in rats. Arch Pharm Res. (2005);28:791-798

https://doi.org/10.1007/BF02977344 